\title{
The rash of West Nile virus infection
}

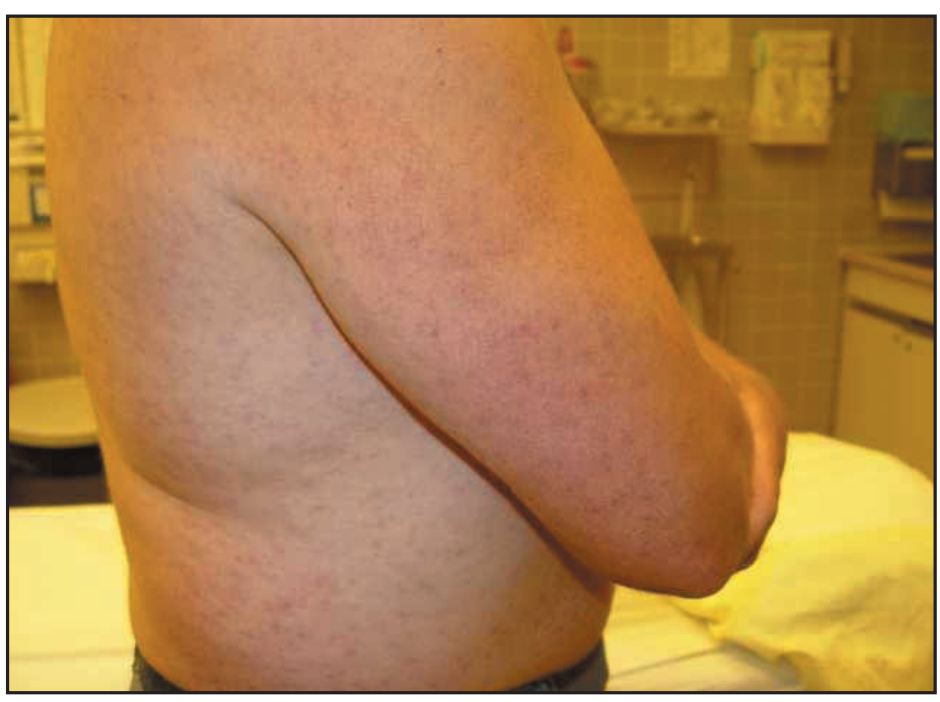

previously healthy 44-yearold man presented to the emergency department of a rural Alberta hospital in August for assessment of a rash. He described a 7-day history of sudden onset of headache accompanied by sore throat, stiff neck and joints, myalgia, nausea, fatigue, fever and chills. He had no cough. The rash, which had been present for 2 days, had begun on the back of the patient's arms and trunk and then had spread across his torso, face and limbs, sparing the palms and soles. The patient had had significant exposure to mosquitoes in the weeks preceding his illness.

The patient appeared ill. His pulse was 97 beats $/ \mathrm{min}$, blood pressure $157 / 95 \mathrm{~mm} \mathrm{Hg}$ and temperature $37.5^{\circ} \mathrm{C}$. His ears and throat were minimally inflamed. He had no palpable lymph nodes, and his chest was clear to auscultation. His rash (Fig. 1) was morbilliform, erythematous, diffuse and painful but nonpruritic, and it consisted of discrete, irregularly shaped macules and minimally elevated papules $2-6 \mathrm{~mm}$ in diame$\approx$ ter. There was no angioedema or purpura. The rash blanched with finger pressure, and some papules 西 were tender to touch.

The patient's leukocyte count was 2.7 (normal $4.0-11.0) \times 10^{\circ} / \mathrm{L}$ and platelet count 132 (normal $150-400) \times 10^{\%} / \mathrm{L}$. Results of serologic testing for West Nile virus $(\mathrm{WNV})$ were negative for IgM initially but were positive on day 19 of his illness. Hemagglutination inhibition testing showed seroconversion for dengue virus (1:80), St. Louis encephalitis virus (1:160) and WNV (1:320), which reflected the broad serologic cross-reactivity of the flavavirus group. Results were negative for Powassan virus (only 1:10). Results of nucleic acid sequencebased amplification and polymerase chain reaction were positive for WNV RNA. Plaque reduction neutralization assay specific for $\mathrm{WNV}$-neutralizing antibodies - the accepted confirmatory test - yielded a positive result. Cultures of throat swab and stool samples were negative for WNV and bacteria.

The patient's rash and symptoms improved within 19 days after onset. He continued to have mild headache for a week and complained of fatigue for a month after the rash disappeared.

The highest incidence of WNV infection in Canada has occurred in the southern Prairies during the hottest and usually driest period, from mid July to the end of September, when the mosquito species that harbour the virus are most prevalent. Two other cases of rash associated with WNV in- fection were seen during the same period as that of our case; as in our case, the rash coincided with increasing severity of symptoms and fever and was associated with neutropenia and thrombocytopenia.

Rash associated with WNV infection is usually described as macular or papular and erythematous. A maculopapular rash was described in $16 \%(3 / 19)$ of WNV-infected patients in hospital in New York and New Jersey in $2000 .^{1} \mathrm{~A}$ similar rash was reported in $27 \%(17 / 67)$ of patients in an outbreak in southcentral Ontario in 2002. ${ }^{2}$ Neither report gave details of the rash onset, duration or association with symptom severity. One report of 3 cases in 2004 described and illustrated an unusual punctate, erythematous, maculopapular rash most pronounced on the extremities.

Rash associated with WNV infection usually appears 3-7 days after the onset of symptoms and accompanies the onset of fever. It lasts between 7 and 14 days and resolves with improvement of other symptoms.

\section{Ronald Gorsche}

Departments of Family Medicine and Community Health Sciences University of Calgary

Peter Tilley

Alberta Provincial Laboratory

for Public Health

Calgary, Alta.

Acknowledgement: We thank Jennifer Alberts and Janice Giles for their valuable assistance in preparing this manuscript.

\section{References}

1. Weis D, Carr D, Kellachan J, Tan C, Phillips M, Bresnitz E, Layton $M$. Clinical findings of West Nile virus infection in hospitalized patients, New York and New Jersey, 2000. Emerg Infect Dis 2001;7(4):654-8.

2. Pepperell C, Rau N, Krajden S, Kern R, Humar A, Mederski B, et al. West Nile virus infection in 2002: morbidity and mortality among patients admitted to hospital in southcentral Ontario. CMA7 2003;168(11):1399-405

3. Anderson RC, Horn KB, Hoang MP, Gottlieb E, Bennin B. Punctate exanthem of West Nile virus infection: report of 3 cases. 7 Am Acad Dermatol 2004;51(5):820-3. 